\title{
Design, Development, and Optimization of Polymeric Based-Colonic Drug Delivery System of Naproxen
}

\author{
Pooja Sharma, Anuj Chawla, and Pravin Pawar \\ Chitkara College of Pharmacy, Chitkara University, Chandigarh-Patiala National Highway, Rajpura, Patiala, Punjab 140401, India \\ Correspondence should be addressed to Pravin Pawar; pravin.pawar@chitkara.edu.in
}

Received 7 August 2013; Accepted 28 August 2013

Academic Editors: J. Ali and A. Nokhodchi

Copyright (C) 2013 Pooja Sharma et al. This is an open access article distributed under the Creative Commons Attribution License, which permits unrestricted use, distribution, and reproduction in any medium, provided the original work is properly cited.

\begin{abstract}
The aim of present investigation deals with the development of time-dependent and $\mathrm{pH}$ sensitive press-coated tablets for colon specific drug delivery of naproxen. The core tablets were prepared by wet granulation method then press coated with hydroxypropyl cellulose (HPC) or Eudragit RSPO : RLPO mixture and further coated with Eudragit S-100 by dip immerse method. The in vitro drug release study was conducted in different dissolution media such as $\mathrm{pH} 1.2,6.8$, and 7.4 with or without rat caecal content to simulate GIT conditions. Surface morphology and cross-sectional view of the tablets were visualized by scanning electron microscopy (SEM). All prepared batches were in compliance with the pharmacopoeial standards. The tablets which are compression coated with HPC followed by Eudragit S-100 coated showed highest in vitro drug release of $98.10 \%$ in presence of rat caecal content. The SEM of tablets suggested that the number of pores got increased in $\mathrm{pH} 7.4$ medium followed by dissolution of coating layer. The tablets coat erosion study suggested that the lag time depends upon the coating concentrations of polymers. A time-dependent hydrophilic polymer and $\mathrm{pH}$ sensitive polymer based press-coated tablets of naproxen were promising delivery for colon targeting.
\end{abstract}

\section{Introduction}

Oral route of administration always receives more attention in comparison to the other drug delivery approaches [1]. Oral site-specific drug delivery systems to the colon have been gaining interests during the past two decades [2]. Colon specific drug delivery system offers several advantages in the treatment of colonic diseases such as ulcerative colitis, amoebiasis, Crohn's disease, irritable bowel syndrome, and colorectal cancer [3]. Delivery of drugs to the colon helps in reducing side effect thereby, achieving high local drug concentration at the afflicted site in the colon, hence resulting in optimal therapeutic effectiveness and good patient compliance $[4,5]$. Different types of dosage forms have been used such as microspheres, nanoparticles, capsules, and hydrogels, have been used for colon specific drug delivery system [6-9]. However, recently more emphasis was laid on the microporous osmotic tablet, matrix tablets, and compression-coated tablets for colon specific drug delivery system because they are convenient to manufacture and produces greater flexibility in designing the dosage form rather than other novel drug delivery systems $[10-12]$. The various approaches that have been studied for colon drug delivery system (CDDS) via oral route include use of $\mathrm{pH}$-sensitive polymers (methacrylic resins and cellulose acetate phthalate) $[13,14]$, time-dependent delivery which includes use of hydroxypropyl cellulose and hydroxypropyl methyl cellulose $[15,16]$, and pressure-dependent system [17].

Time-dependent drug release systems can be formulated by applying coats onto drug cores which are capable of delaying the release through different mechanisms [18]. However, drawback associated with these deliveries is the lack of site specificity due to large variation in gastric emptying time. Thus, time controlled and site specificity are difficult. A simple $\mathrm{pH}$-dependent approach is also not suitable to be used alone because of premature release of drug. Therefore, these problems can be overcome by using the combination of both time-dependent and $\mathrm{pH}$-dependent polymers [19].

HPC is primarily used as a pharmaceutical additive for various purposes such as a tablet binder, film-coating material, and as a delayed release system [20]. The use of hydroxypropyl cellulose (HPC) has been reported earlier as a time released preparation, and the in vivo studies on beagle dogs demonstrated that the HPC press-coated tablets showed 
TABLE 1: Composition of naproxen sodium core, press-coated tablets, and enteric-coated tablets.

\begin{tabular}{|c|c|c|c|c|c|c|c|c|c|}
\hline Ingredients & NF1 & NF2 & NF3 & NF4 & NF5 & NF6 & NF7 & NF8 & NF9 \\
\hline Drug & + & + & + & + & + & + & + & + & + \\
\hline Lactose & + & + & + & + & + & + & + & + & + \\
\hline Starch & + & + & + & + & + & + & + & + & + \\
\hline Magnesium Stearate & + & + & + & + & + & + & + & + & + \\
\hline $\mathrm{HPC}$ & - & + & + & + & + & - & - & - & - \\
\hline RSPO : RLPO & - & - & - & - & - & + & + & + & + \\
\hline $\begin{array}{l}{ }^{*} \text { ED S-100 } \\
2.5 \% \mathrm{w} / \mathrm{v}\end{array}$ & - & - & + & - & - & - & + & - & - \\
\hline $\begin{array}{l}{ }^{*} \mathrm{ED} S-100 \\
5.0 \% \mathrm{w} / \mathrm{v}\end{array}$ & - & - & - & + & - & - & - & + & - \\
\hline $\begin{array}{l}{ }^{*} \mathrm{ED} S-100 \\
7.5 \% \mathrm{w} / \mathrm{v}\end{array}$ & - & - & - & - & + & - & - & - & + \\
\hline
\end{tabular}

${ }^{+}$Sign indicates presence of ingredient.

- Sign indicates absence of ingredient.

* Eudragit S-100.

lag time of $4 \mathrm{~h}$ [21]. The molecular weight of HPC-EF has greater influence on its compactibility properties that is, the compactibility of HPC-EF increases due to its low molecular weight [22-24]. Therefore, taking into consideration all the properties, of HPC-EF, the core tablet of naproxen sodium was press coated with hydroxypropylcellulose which is a $\mathrm{pH}$ independent hydrophilic and time-dependent polymer and releases the drug after predetermined lag time.

However, the lag time of $4 \mathrm{~h}$ was not sufficient to target the drug delivery to colon. Therefore, the press-coated tablets were coated with Eudragit S-100 coating which retarded the release in upper part of GIT and showed the lag phase of $6 \mathrm{~h}$, assuring sufficient lag time for delivering the drug to the colon [25].

Taking the above information in view, the present investigation based on the utilization of time-dependent polymer such as hydroxypropyl cellulose and $\mathrm{pH}$-sensitive polymer, that is, Eudragit S-100 for colon drug delivery of naproxen sodium.

Naproxen sodium, 2-napthaleneacetic acid, and 6 methoxy-a-methyl sodium salt are a nonselective COX inhibitor widely used as analgesic and in treatment of rheumatoid arthritis, colitis [26]. Moreover, because of the same mode of action, it shows synergistic action with that of anticancer drugs [27]. Piao et al. prepared a coated naproxen tablets to reduce intestinal tissue damage by delivering the drug specifically to colon for the treatment of colonic diseases like colitis and crohn's disease [28].

Therefore, by considering all the above data, the naproxen sodium was used as a model drug in colon delivery system using two different polymers: HPC-EF and Eudragit S-100, so that it can deliver the drug locally in colon. Such type of formulation also minimizes upper GI tract side effects of naproxen sodium and help in providing therapeutic benefits.

\section{Materials and Methods}

2.1. Materials. Naproxen sodium was obtained as a complimentary sample by Microlabs Pvt Ltd., Banglore, India.
Hydroxypropylcellulose EF (HPC) was received from Matrix Lab, Hyderabad, India. Eudragit S-100, Eudragit RLPO, and Eudragit RSPO were procured from Evonik industries, Mumbai, India. All other chemicals used were of analytical grade.

\subsection{Methods}

2.2.1. Preparation of Naproxen Sodium Core Tablets. The core tablets of naproxen sodium were prepared by wet granulation. The weighed quantity of drug and lactose was mixed uniformly and granulated using starch paste as binding agent. The starch paste (5\%) was prepared by dissolving corn starch powder in required quantity of warm distilled water. The wet mass was passed through 22\# sieve, and the granules were dried in a tray drier for $15 \mathrm{~min}$ at $45^{\circ} \mathrm{C}$. The dried granules were then passed through 22\# sieve and mixed uniformly with magnesium stearate as lubricant. The prepared granules were then compressed on multiple punch tablet machine (AK Industries, Nacodar, India) using $8 \mathrm{~mm}$ concave punches.

2.2.2. Preparation of Press-Coated Core Tablets. The core tablets were press coated with a polymers hydroxypropylcellulose/Eudragit RSPO : RLPO (Table 1). One half of the polymer was filled into the die cavity to make a powder bed at bottom of a single punch tablet machine using a flat punch of $12 \mathrm{~mm}$ diameter. The core tablet was placed in the centre on the above powder bed, followed by filling of the remaining half quantity of the polymer. The tablet was then compressed and the presscoated tablets were evaluated and used for further coating.

2.2.3. Enteric Coating of Press-Coated Tablets. The presscoated tablets were further coated with $\mathrm{pH}$-dependent polymer Eudragit S-100 using dip immerse method. A different concentration (i.e., 2.5, 5.0, and 7.5\%) of coating solution of Eudragit S-100 was prepared in a mixture of isopropyl alcohol (IPA) and acetone. The coated tablets were dried at room temperature for $24 \mathrm{hrs}$ and kept in vacuum dessicator. 


\subsubsection{Evaluation of Granules}

Angle of Repose. Angle of repose is defined as the maximum angle possible between the surface of pile of powder ( $5 \mathrm{gm}$ ) and horizontal plane. The angle of repose is used to determine the flow characteristics of the powder. This can be calculated by the following formula:

$$
\tan \theta=\frac{h}{r}
$$

where $\theta$ is angle of repose, $h$ is height of pile, and $r$ is radius of pile.

Bulk Density. A weighed amount (9-13 gm) of granules was poured in the graduated measuring cylinder $(25 \mathrm{~mL}$ capacity). The initial volume of poured granules was then noted. Calculate the bulk density using the following formula:

$$
\text { Bulk density }(\mathrm{BD})=\frac{\text { Mass of granules }}{\text { Initial volume of granules }} \text {. }
$$

Tapped Density. A weighed amount (9-13 gm) of granules was poured in measuring cylinder $(25 \mathrm{~mL}$ capacity). The cylinder is then mechanically tapped after observing the initial volume. Noted the volume or mass readings of tapped granules until little further volume or mass change is observed:

$$
\text { Tapped density }=\frac{\text { Mass of granules }}{\text { Tapped volume of granules }} \text {. }
$$

Compressibility Index. The compressibility index of granules can be determined by Carr's compressibility index by the equation:

$$
\text { Carr's index }(\%)=\frac{\left(V_{o}-V_{f}\right)}{V_{o}} \times 100,
$$

where $V_{o}$ is unsettled apparent volume and $V_{f}$ is final tapped volume.

Hausner's Ratio. It was determined by the ratio of tapped density to bulk density:

$$
\text { Hausner's ratio }=\frac{\text { Tapped density }}{\text { Bulk density }} .
$$

\subsubsection{Drug Excipient Compatibility Study}

Fourier Transform Infrared Spectroscopy (FTIR). The infrared spectra of naproxen sodium, hydroxypropyl cellulose, Eudragit S-100, physical mixture of press-coated tablet (naproxen sodium, hydroxypropyl cellulose), and physical mixtures of coated tablet (naproxen sodium, hydroxypropyl cellulose, and Eudragit S-100) were recorded in the range of 4000 to $400 \mathrm{~cm}^{-1}$ using FTIR spectrophotometer (Mode spectrum RX 1, Perkin Elmer, UK). The IR spectra for the samples were obtained by potassium bromide $(\mathrm{KBr})$ disk method.

\subsubsection{Evaluation of Tablets}

Weight Variation. Twenty tablets from each formulation were randomly selected and individually weighed. The average weight and standard deviation was also calculated.

Hardness. The tablet crushing strength was determined by Monsanto hardness tester (Interlabs, Ambala, India). A tablet is placed between the anvils, and reading was noted of the force which causes tablet to break.

Tablet Dimensions. The diameter and thickness of the tablets were determined using a digital vernier calliper (CD-6 ${ }^{\prime \prime} \mathrm{CSX}$, Mitutoyo Digimatic Calliper, Japan).

Friability. Six tablets from each batch were weighed and placed in Roche friabilatar (902, EI Products, Panchkula, India). The apparatus was rotated at $25 \mathrm{rpm}$ for $4 \mathrm{~min}$. After rotations the tablets were dedusted and again weighed. The percentage friability of the tablets was measured by using the following formula:

$$
\% \text { Friability }=\frac{\text { Initial weight }- \text { Final weight }}{\text { Initial weight }} \times 100 \text {. }
$$

2.2.7. Determination of Drug Content. Twenty tablets from each formulation were weighed and finely powdered using mortar and pestle. A quantity equivalent to $50 \mathrm{mg}$ of naproxen sodium was transferred to $100 \mathrm{~mL}$ volumetric flask containing phosphate buffer $\mathrm{pH} 7.4$ and mixed thoroughly. The solution was filtered and analyzed for its drug content using UV/Vis spectrophotometer (AU-2701, Systronics, Mumbai, India) at $272 \mathrm{~nm}$.

2.2.8. In Vitro Drug Release Studies. An in vitro drug release study was carried out using USP type II dissolution apparatus (DS8000, LABINDIA, Navi Mumbai, India) in a $900 \mathrm{~mL}$ of dissolution medium at temperature $37 \pm 0.5^{\circ} \mathrm{C}$ and stirring speed of $100 \mathrm{rpm}$. The dissolution test was performed in three different dissolution mediums, that is, $\mathrm{pH} 1.2,6.8$, and 7.4, in order to mimic the GIT conditions. The tablets were first kept in $\mathrm{pH} 1.2(0.1 \mathrm{~N} \mathrm{HCl})$ for $2 \mathrm{~h}$. After $2 \mathrm{~h}$ the dissolution media were replaced with phosphate buffer $\mathrm{pH} 6.8$, and dissolution was carried out for $3 \mathrm{~h}$; then the $\mathrm{pH}$ of dissolution media was adjusted to 7.4, and the drug release study was continued up to $24 \mathrm{~h}$. A $5 \mathrm{~mL}$ of sample was withdrawn from the dissolution media at a specified time intervals, followed by replacing with same aliquot of fresh dissolution media to maintain sink conditions. The samples were then analysed using UV/Vis spectrophotometer at $272 \mathrm{~nm}$. The in vitro dissolution study was performed in triplicate [29].

Preparation of Rat Caecal Content Medium. The rat caecal content medium has the similar contents to that of the intestinal microflora; therefore it was prepared to study further drug release of tablet and to assess the susceptibility of formulation to colonic bacteria. Wistar rats weighing 100-150 g, maintained on normal diet and $1 \mathrm{~mL}$ of $1 \% \mathrm{w} / \mathrm{v}$ solution of HPC/Eudragit S-100 in water, were administered with the help of Teflon tubing directly into the stomach region via 
oral cavity. The treatment was continued for 6 days to induce enzyme responsible for degradation of HPC/Eudragit S-100. At least $45 \mathrm{~min}$ before the commencement of dissolution study, the rats were sacrificed, and the abdomen was cut to isolate caecum. The caecal content was immediately transferred into a tared beaker containing phosphate buffer $\mathrm{pH} 7.4$ previously bubbled with nitrogen to obtain $4 \% \mathrm{w} / \mathrm{v}$ concentration caecal content equivalent to $8 \mathrm{~g}$ that was added to $200 \mathrm{~mL}$ of buffer to give a final caecal dilution of $4 \%$ [30].

\subsubsection{Drug Release Study in Presence of Rat Caecal Content.} The drug release study in presence of caecal content was performed on batches NF2 to NF5 using dissolution test apparatus with slight modifications in a procedure. The initial studies were carried out in same manner, that is, in $\mathrm{pH} 1.2$ for $2 \mathrm{~h}$ and $\mathrm{pH} 6.8$ for $3 \mathrm{~h}$. After $5 \mathrm{~h}$ tablets were placed in $200 \mathrm{~mL}$ phosphate buffer $\mathrm{pH} 7.4$ containing rat caecal medium, and release studies were carried out till $24 \mathrm{~h}$. The required amount of samples $(2 \mathrm{~mL})$ was taken at specified time intervals and replenished with same volume of fresh dissolution media maintained at $37 \pm 0.5^{\circ} \mathrm{C}$. The experiment was carried out in the presence of continuous supply of nitrogen. The samples were then analyzed using a UV spectrophotometer [31].

2.2.10. Scanning Electron Microscopy. The tablets of optimized batch were removed from the dissolution apparatus at predetermined time intervals, and their surface morphology and cross-sectional view were then visualized using scanning electron microscope (JSM 6100 Jeol, Japan). The gold sputter coating of samples was done prior to examination to make them electrically conductive.

2.2.11. Coat Erosion Study. The coat erosion study was performed in the same manner as the dissolution study at $\mathrm{pH} 6.8$ and $\mathrm{pH} 7.4$ phosphate buffer media [32]. Before proceeding dissolution study, the initial weight of the tablet was measured $\left(W_{i}\right)$. At a specified time interval, tablets were taken out from the media, dried at $60^{\circ} \mathrm{C}$ (until constant weight was not achieved), and reweighed $\left(W_{d}\right)$. The $\%$ coat erosion was calculated using the following formula [33]:

$$
\text { Coat erosion }(\%)=\frac{W_{d}}{W_{i}} \times 100 \text {. }
$$

2.2.12. Drug Release Kinetics. To study the drug release kinetics, the in vitro release data were fitted to zero order (cumulative percentage of drug released versus time), first order (log cumulative percent of drug remaining to be released versus $\log$ time), and Higuchi kinetics (cumulative percent of drug release versus square root of time).

The drug release mechanism was determined using Korsmeyer-Peppas equation by plotting the graph between log percentage of drug released versus log time. The exponent " $n$ " indicates the mechanism of drug release calculated through the slope of the straight line:

$$
\frac{M_{t}}{M_{f}}-K t^{n}
$$

TABLE 2: Micromeritic properties of granules of naproxen sodium core tablet.

\begin{tabular}{lc}
\hline Angle of repose $\left(^{\circ}\right) \pm$ S.D & $23.41 \pm 1.32$ \\
Bulk density $(\mathrm{gm} / \mathrm{mL}) \pm$ S.D & $0.36 \pm 0.004$ \\
Tapped density $(\mathrm{gm} / \mathrm{mL}) \pm$ S.D & $0.40 \pm 0.003$ \\
Carr's index $(\%) \pm$ S.D & $9.84 \pm 1.09$ \\
Hausner's ratio & $1.15 \pm 0.03$ \\
\hline
\end{tabular}

Mean \pm S.D. $(n=3)$.

where $M_{t}$ is amount of drug release at time $t, M_{f}$ is amount of drug release at infinite time, $K=$ release rate constant, and $n$ is diffusional exponent indicates the mechanism of drug release.

If value of $n$ falls between 0.5 and 1.0 ; it is termed as nonfickian release, while in case of Fickian diffusion, $n=0.5$. For zero order release case II transport $n=1$; on the other hand if $n>1$ then it indicates supercase II transport [34].

2.2.13. Stability Studies. The stability study was conducted according to ICH guidelines. All the formulations were stored in aluminium packaging laminated with polyethylene and kept in humidity chamber at accelerated and room temperature conditions for 6 months. The samples were withdrawn at a specified time intervals of 0 days, 1 month, 2 month, 3 month, and 6 month. The samples were evaluated for their physical characteristics (colour) and drug content. The degradation rate constant $\left(K_{\mathrm{cal}}\right)$, shelf life $\left(t_{90}\right)$, and initial drug concentrations providing 2 years shelf life $\left(\mathrm{Int}_{\mathrm{cal}}\right)$ were determined [35].

\section{Results}

The naproxen sodium is a nonsteroidal anti-inflammatory drug and has poor compressibility. Therefore, the granules of naproxen sodium were prepared by using diluents and binding agent. The granules used for preparing the core tablets of naproxen sodium were evaluated for angle of repose, bulk density, tapped density, compressibility index, and Hausner's ratio. The angle of repose was found to be $23.41^{\circ} \pm$ 1.32 exhibited the excellent flow properties. The packing properties of the material can be evaluated by the bulk and tapped density. The bulk density and tapped density were $0.36 \pm 0.004 \mathrm{gm} / \mathrm{mL}$, and $0.40 \pm 0.003 \mathrm{gm} / \mathrm{mL}$, respectively, which indicate good flowability of the granules [36]. Moreover, the compressibility index also known as Carr's index was found to be $9.84 \pm 1.09$, and Hausner's ratio $(1.15 \pm 0.03)$ also given in Table 2 indicates that the granules formed were easily compressible.

3.1. Fourier Transform Infrared Spectroscopy (FTIR). FT-IR spectra of the drug, polymers, and their physical mixtures are depicted in Figure 1. The drug sample showed characteristic functional group peaks at $1252 \mathrm{~cm}^{-1}$ due to $\mathrm{C}-\mathrm{O}$ stretching (acid), $1583 \mathrm{~cm}^{-1}$ due to COO- stretching, C-C aromatic stretching at $1631 \mathrm{~cm}^{-1}$, and $\mathrm{C}-\mathrm{H}$ aliphatic stretch at $2840 \mathrm{~cm}^{-1}$. HPC shows a broad peak at $3460 \mathrm{~cm}^{-1}$ which may be due to $\mathrm{O}-\mathrm{H}$ stretching vibration, whereas the peak 


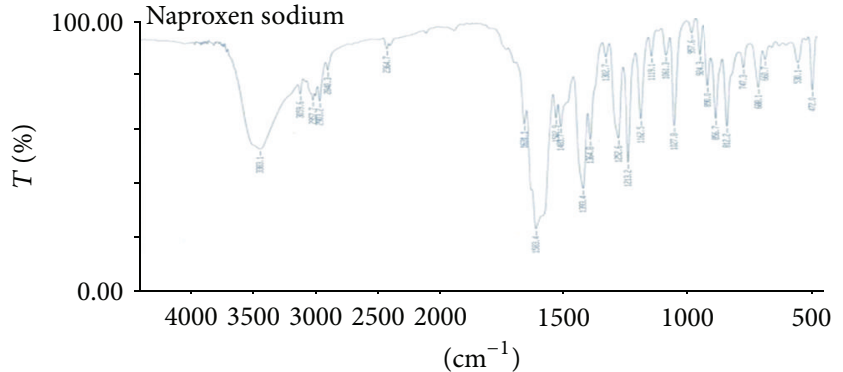

(a)

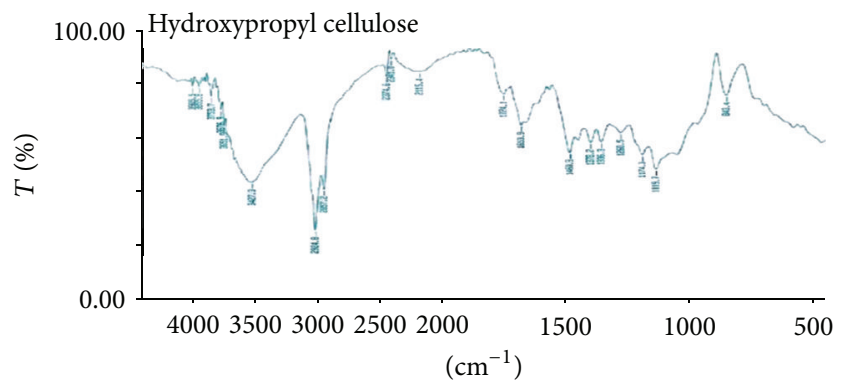

(c)

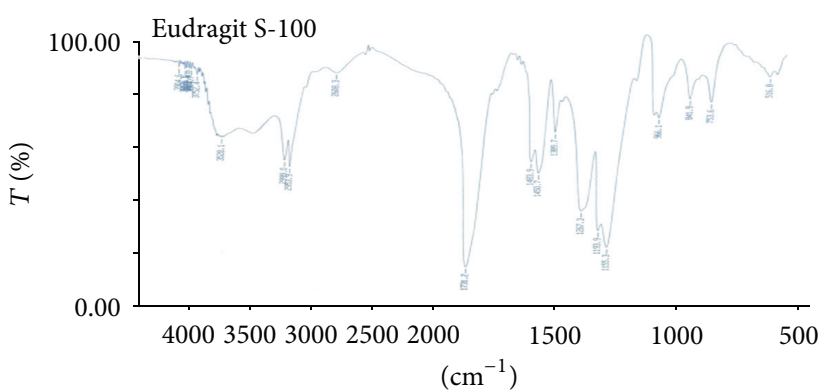

(b)

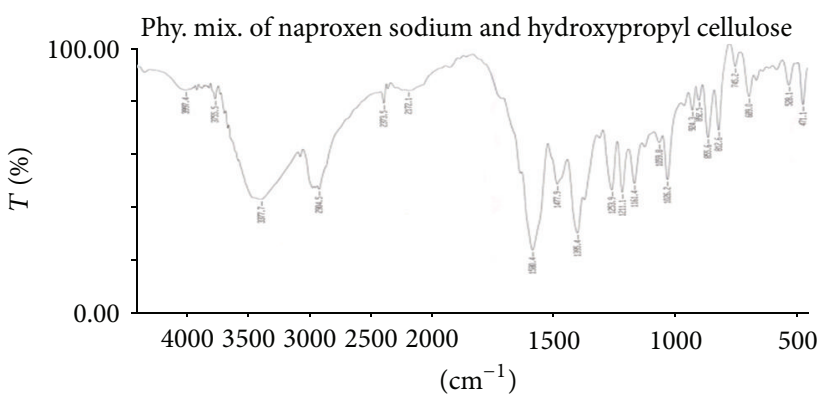

(d)

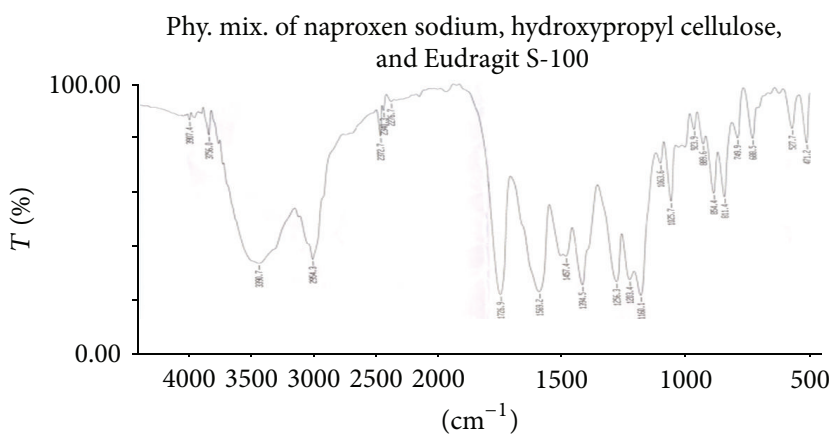

(e)

FIGURE 1: Fourier transform infrared spectra of naproxen sodium, Eudragit S-100, hydroxypropyl cellulose, physical mixture (naproxen sodium and hydroxyl propyl cellulose), and physical mixture (naproxen sodium, hydroxyl propyl cellulose, and Eudragit S-100).

shown at $2924 \mathrm{~cm}^{-1}$ is present due to $\mathrm{C}-\mathrm{H}$ asymmetric stretching vibration. The peaks appeared at $1770 \mathrm{~cm}^{-1}$, and $1260 \mathrm{~cm}^{-1}$ was observed due to $\mathrm{C}=\mathrm{O}$ stretching and $\mathrm{C}-\mathrm{O}$ stretching, respectively. In physical mixture of press-coated tablet, the peaks at $1253.9 \mathrm{~cm}^{-1}, 1580.4 \mathrm{~cm}^{-1}, 855.6 \mathrm{~cm}^{-1}$, and $2924.8 \mathrm{~cm}^{-1}$ indicate the presence of naproxen sodium and hydroxypropyl cellulose without any ineraction. The FT-IR of physical mixture of coated tablets showed the characteristic peak of the drug, and polymers revealed that all peaks were easily detectable in the physical mixture. This shows that there is no interaction between drug and excipient.

3.2. Physicochemical Properties of Naproxen Sodium Tablets. The physicochemical properties of prepared naproxen sodium press-coated tablets were depicted in Table 3. The weight variation values for all formulations (NF1 to NF9) were found between 251.24 and $508.15 \mathrm{mg}$. All the weight variation values of tablets were complying with official compendia, and there were no effect of press coating as well as Eudragit S-100 coating on tablet weight variation.

The mean thickness of all the formulated batches of tablets was measured, and the results revealed that batch NF1 showed less thickness of $4.01 \pm 0.02 \mathrm{~mm}$, whereas the thickness of press-coated formulations NF2 and NF6 got increased, that is, $4.62 \pm 0.02$, and $4.57 \pm 0.02$ respectively. The thickness of press-coating tablets further increased, and the value varies from $4.63 \pm 0.02$ to $4.86 \pm 0.02 \mathrm{~mm}$. The diameter and friability of the batches were between 8.01 to $12.94 \mathrm{~mm}$ and 0.22 to $0.63 \%$, respectively. On the other hand, the percentage friability that was less than $1 \%$ indicates that the friability is within the specified limit. The hardness of the core tablet usually kept low, that is, $4.09 \pm 0.59$, so that press-coated polymer HPC get sticks to the core tablet [37], whereas the hardness of the coated tablets varies from 6.05 to $6.59 \mathrm{~kg} / \mathrm{cm}^{2}$. The formulation NF2 showed maximum \% drug content, that is, $96.37 \pm 1.91$ as compared with other 
TABLE 3: Physicochemical parameters of naproxen sodium core, press-coated tablets, and enteric-coated tablets.

\begin{tabular}{|c|c|c|c|c|c|c|}
\hline Formulation code & Weight variation (mg) & Thickness (mm) & Diameter $(\mathrm{mm})$ & Hardness $\left(\mathrm{kg} / \mathrm{cm}^{2}\right)$ & Friability (\%) & Drug content (\%) \\
\hline NF1 & $251.24 \pm 2.24$ & $4.01 \pm 0.02$ & $8.01 \pm 0.02$ & $4.09 \pm 0.59$ & $0.63 \pm 0.03$ & $95.27 \pm 2.03$ \\
\hline NF2 & $500.31 \pm 2.26$ & $4.62 \pm 0.02$ & $12.88 \pm 0.02$ & $6.48 \pm 0.59$ & $0.53 \pm 0.02$ & $92.36 \pm 1.91$ \\
\hline NF3 & $501.19 \pm 2.19$ & $4.78 \pm 0.02$ & $12.03 \pm 0.02$ & $6.05 \pm 0.59$ & $0.25 \pm 0.03$ & $96.37 \pm 2.09$ \\
\hline NF4 & $502.15 \pm 2.21$ & $4.82 \pm 0.02$ & $12.08 \pm 0.02$ & $6.54 \pm 0.67$ & $0.28 \pm 0.02$ & $93.99 \pm 1.48$ \\
\hline NF5 & $502.07 \pm 2.26$ & $4.86 \pm 0.02$ & $12.92 \pm 0.02$ & $6.47 \pm 0.59$ & $0.20 \pm 0.02$ & $95.61 \pm 1.95$ \\
\hline NF6 & $503.15 \pm 2.23$ & $4.57 \pm 0.02$ & $12.81 \pm 0.02$ & $6.34 \pm 0.67$ & $0.46 \pm 0.02$ & $94.49 \pm 1.86$ \\
\hline NF7 & $500.68 \pm 2.28$ & $4.53 \pm 0.02$ & $12.86 \pm 0.02$ & $6.25 \pm 0.59$ & $0.29 \pm 0.02$ & $94.41 \pm 1.90$ \\
\hline NF8 & $501.63 \pm 2.28$ & $4.57 \pm 0.02$ & $12.74 \pm 0.02$ & $6.59 \pm 0.67$ & $0.23 \pm 0.02$ & $95.61 \pm 1.96$ \\
\hline NF9 & $502.03 \pm 2.26$ & $4.59 \pm 0.02$ & $12.94 \pm 0.02$ & $6.35 \pm 0.67$ & $0.22 \pm 0.01$ & $94.36 \pm 2.03$ \\
\hline
\end{tabular}

Mean \pm S.D. $(n=3)$.

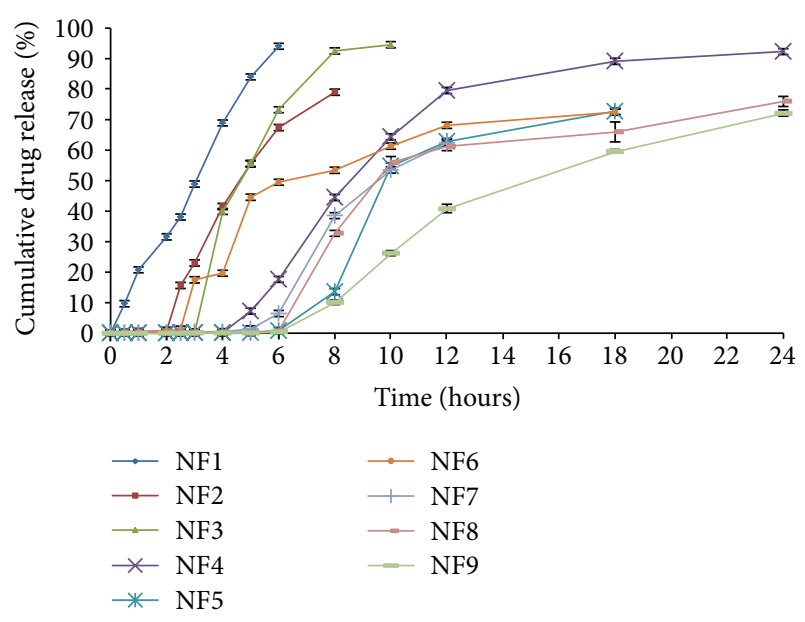

FIGURE 2: In vitro release profiles showing the cumulative percent of naproxen sodium release from core (NF1), press-coated tablets (NF2, NF6), and Eudragit S-100 coated tablets (NF3, NF4, NF5, NF7, NF8, and NF9) without rat caecal content. Data are expressed as mean \pm S.D. $(n=3)$.

formulations of tablets. The remaining formulations showed the $\%$ drug content in-between the range of $94.36 \pm 2.03$ to $95.61 \pm 1.96 \%$.

\subsection{In Vitro Drug Release Studies without Rat Caecal Content.} The dissolution profile of core tablet (NF1) was studied in phosphate buffer $\mathrm{pH} 7.4$ to examine the release profile of the core tablet. The study resulted in $94.05 \pm 1.46 \%$ of drug release within a period of $6 \mathrm{~h}$ in $\mathrm{pH} 7.4$ media (Figure 2). The press-coated tablets batch NF2 and NF6 were subject to dissolution studies at different $\mathrm{pH}$ media, that is, acid buffer media of $\mathrm{pH}$ 1.2, phosphate buffer $\mathrm{pH}$ 6.8, and $\mathrm{pH}$ 7.4. It was observed that NF2 formulation which was press-coated with HPC showed $79.01 \pm 2.02 \%$ drug release for a period of $8 \mathrm{~h}$. On the other hand, Eudragit RSPO:RLPO mixture press-coated batch NF6 exhibited $80.47 \pm 1.11 \%$ of cumulative drug release for $24 \mathrm{~h}$ (Figure 3 ). The press coated tablets were enteric coated with different concentrations of Eudragit S-100 polymer given in Table 1 . On analyzing \% cumulative drug release, it was found that the formulations NF3, NF4, and NF5

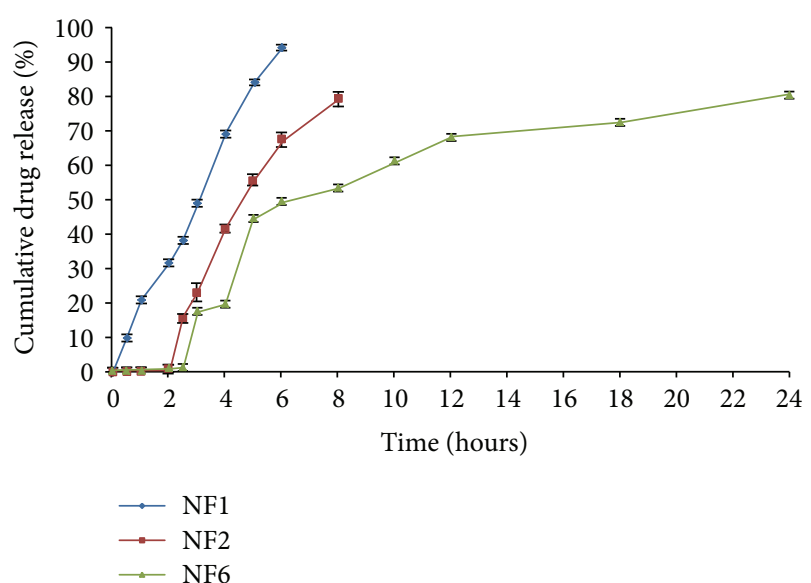

FIGURE 3: Comparative in vitro release profiles of naproxen sodium core tablets (NF1), press-coated HPC tablets (NF2), and press-coated Eudragit RSPO : RLPO tablets (NF6). Data are expressed as mean \pm S.D. $(n=3)$.

demonstrated more drug release, that is, $94.54 \pm 1.75,92.32 \pm$ $2.27,83.19 \pm 1.33 \%$, respectively (Figure 4). Formulations NF7 to NF9 provide cumulative release in the range of $72.17 \pm 1.02$ to $79.47 \pm 2.38$ (Figure 5). However, these results suggest that the formulations NF4, NF5, NF7, NF8, and NF9 prevent the drug release in upper part of GIT, whereas NF3 started eroding in small intestine, that is, in $\mathrm{pH} 6.8$.

3.4. In Vitro Drug Release Studies in the Presence of Rat Caecal Content. Eventually, the release of drug from formulations NF1 to NF5 was analyzed in colonic environment containing phosphate buffer $\mathrm{pH} 7.4$ in the presence of $4 \% \mathrm{w} / \mathrm{v}$ rat caecal contents to precisely examine the release behaviour of these formulations in colonic environment. Amongst the formulations, the optimized formulation, that is, NF4, showed the maximum percentage of cumulative drug release $98.10 \pm$ $1.61 \%$ in the colon region. Figure 6 demonstrated that all the formulations of tablet showed more than $5 \%$ of drug release in the presence of rat caecal content in comparison to the in vitro drug release in the absence of rat caecal content which has been shown in Figure 2. 


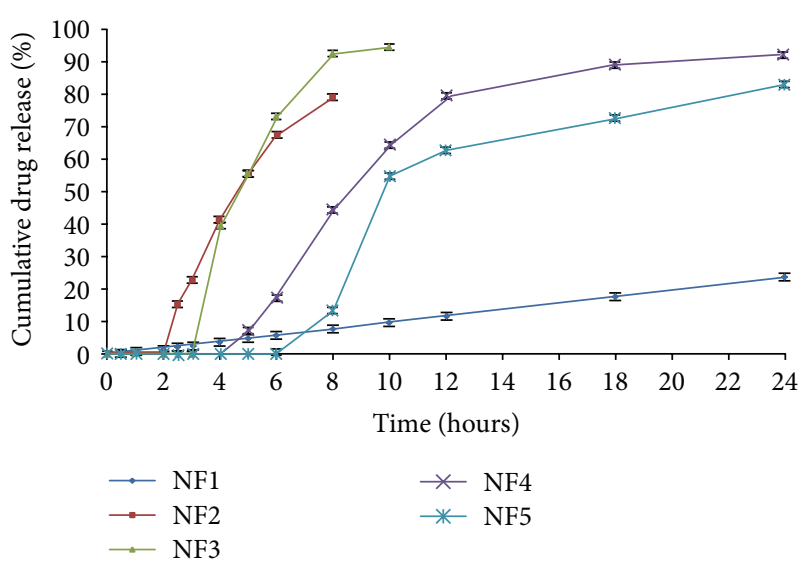

FIGURE 4: In vitro release profiles of naproxen sodium core tablets (NF1), press-coated HPC tablets (NF2), and press-coated HPC tablets enteric coated with Eudragit S-100 in different concentrations of $2.5 \%, 5.0 \%$, and $7.5 \%$ (NF3, NF4, and NF5), respectively. Data are expressed as mean \pm S.D. $(n=3)$.

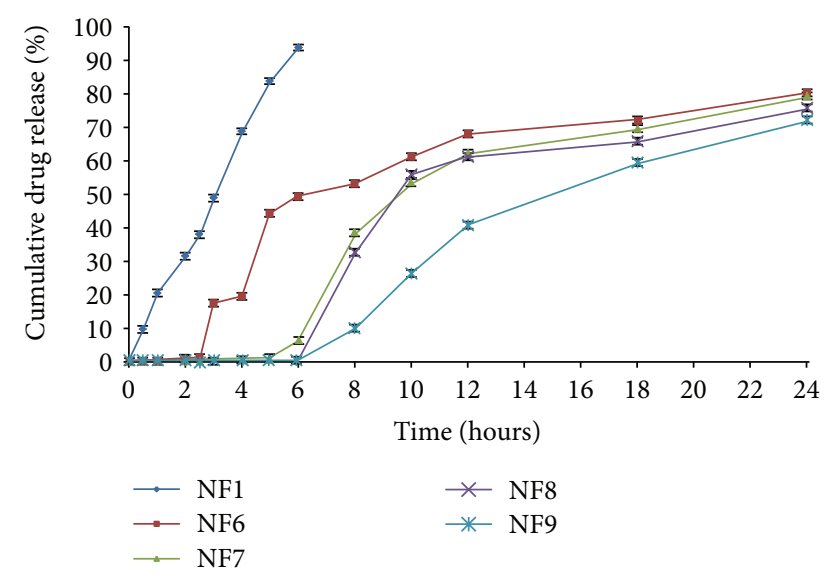

Figure 5: Comparison of in vitro release profiles of naproxen sodium core tablets (NF1), press-coated Eudragit RSPO:RLPO formulation (NF6), and press-coated Eudragit RSPO : RLPO tablets enteric coated with Eudragit S-100 in different concentrations of $2.5 \%, 5.0 \%$, and $7.5 \%$ (NF7, NF8, and NF9), respectively. Data are expressed as mean \pm S.D. $(n=3)$.

3.5. Scanning Electron Microscopy. The information regarding the different behaviour of the coated tablets was obtained by the SEM analyses. No pores were detected in the tablet before dissolution study. During dissolution studies, the SEM analyses of tablets were done at different type intervals and in different media conditions. Figure 7 presented that the tablet does not erode in acidic media. However, very minute pores were seen in $\mathrm{pH} 6.8$ which got increased in $\mathrm{pH} 7.4$ phosphate buffer.

3.6. Coat Erosion Study. The coat erosion study was done in $\mathrm{pH} 6.8$ and $\mathrm{pH} 7.4$ for formulations NF3, NF4, and NF5 as shown in Figure 8. It was demonstrated that initially the coating remains $100 \%$ in all said three formulations. At $\mathrm{pH}$

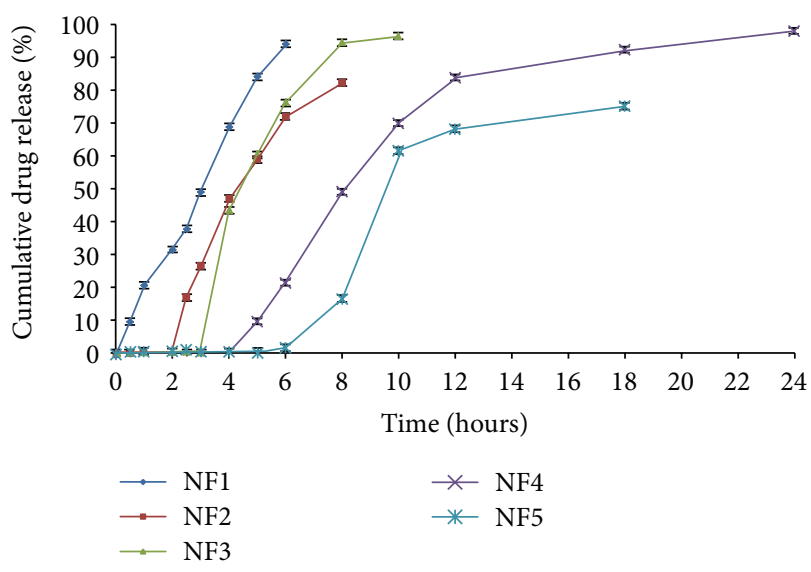

FIGURE 6: In vitro release profiles of various formulations of naproxen sodium (NF1, NF2, NF3, NF4, and NF5) in presence of $4 \%$ $\mathrm{w} / \mathrm{v}$ rat caecal content. Data are expressed as mean \pm S.D. $(n=3)$.

6.8 , the behaviour of coating remains same for all formulations of tablet except NF3 batch. In case of NF3, the coating erodes fastly results only $41.0 \pm 2.0 \%$ of coating was present on the surface of tablet at $\mathrm{pH} 7.4$ as compare to other formulations. On the other hand in formulations NF4 and NF5, the erosion was observed in coating of negligible manner at $\mathrm{pH} 7.4$ at initial stage. Later on at the time points $7 \mathrm{~h}$ and $9 \mathrm{~h}$, the coating was decreased to half in case of NF4 and NF5 formulations, respectively.

3.7. Drug Release Kinetics. To determine the quantitative analysis of the values obtained from drug release profile, various mathematical models are used. The goodness of fit was evaluating using regression coefficient $\left(r^{2}\right)$ values. The regression coefficients $\left(r^{2}\right)$ for all the formulations using different kinetics equation are listed in Table 4 . The table data revealed that in vitro release from the tablets is better explained by the Higuchi equation, where the rate constants obtained from the slope provide the highest linearity. To explore the drug release mechanism, in vitro release results were further fitted to the K-P model. This model analyses the release of polymeric dosage forms, either in cases when the release mechanism is not well known or when more than one type of release phenomena are involved. Among all formulations, the formulation NF1, NF2, and NF6 followed Fickian kinetics ( $n \leq 0.45$ ), and the remaining formulations followed nonFickian kinetics $(n \geq 0.45)$.

3.8. Stability Studies. The stability studies of all the formulations were conducted at accelerated and room temperature storage conditions, and the tablets were examined for physical appearance and drug content. The results indicated that no change in physical appearance was noticed upon visual inspection of the tablets. All the formulations showed more than $90 \%$ of drug content during both accelerated and room temperature storage conditions (Figure 9). The degradation rate constants $\left(k_{\text {cal }}\right)$ and shelf life $\left(t_{90}\right)$ at room temperature for all formulations range between 1.11 to 2.60 day $^{-1}$ and 403.84 to 945.94 days, respectively. 


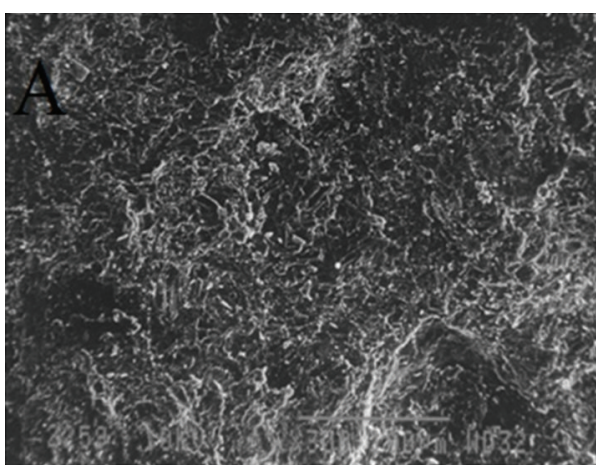

(a)

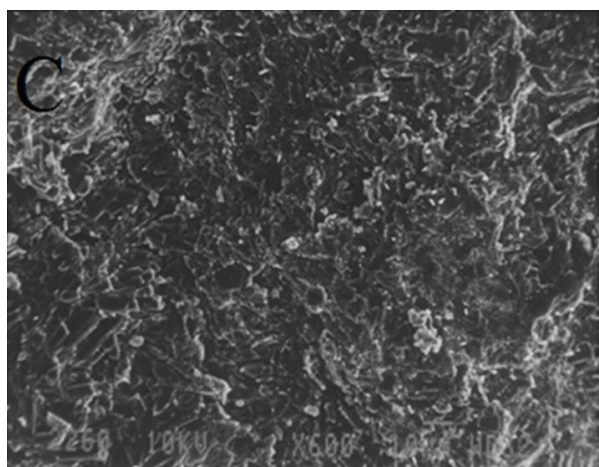

(c)

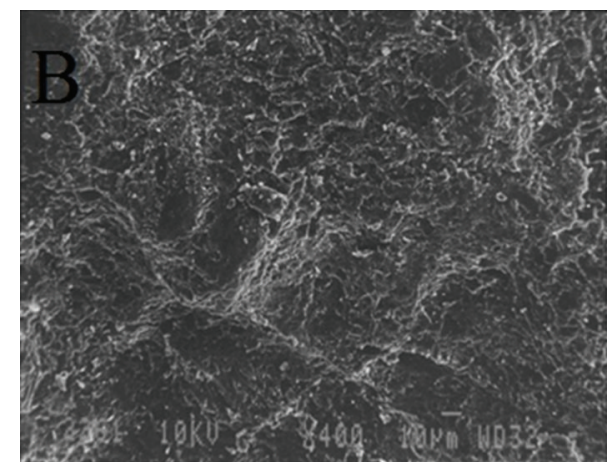

(b)

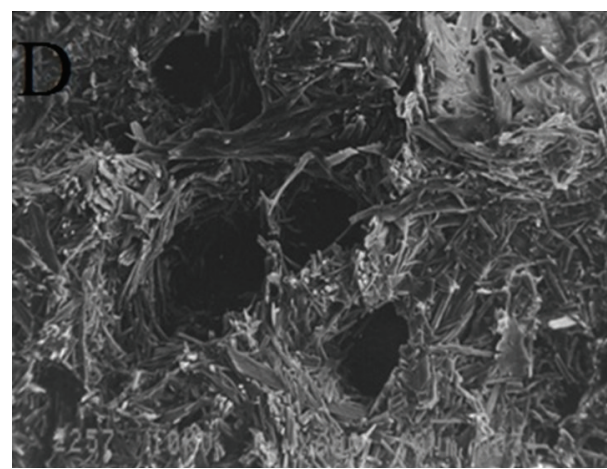

(d)

FIGURE 7: Scanning electron microscopy of optimized batch (NF4), obtained before dissolution (a), after $2 \mathrm{~h}$ dissolution at pH 1.2 (b), after $5 \mathrm{~h}$ dissolution at $\mathrm{pH} 6.8$ (c), and during dissolution study at $\mathrm{pH} 7.4$ (d).

TABLE 4: Regression coefficient $\left(r^{2}\right)$ values of drug release data calculated from various drug release kinetic models and $n$ value in accordance with Korsemeyer-Peppas.

\begin{tabular}{lccrr}
\hline \multirow{2}{*}{ Formulation code } & Zero order & First order & Higuchi & \multicolumn{2}{c}{ Korsemeyer-Peppas } \\
& $r^{2}$ & $r^{2}$ & $r^{2}$ & 0.399 \\
NF1 & 0.892 & 0.986 & 0.990 & 0.979 \\
NF2 & 0.896 & 0.986 & 0.992 & 0.976 \\
NF3 & 0.950 & 0.884 & 0.988 & 0.978 \\
NF4 & 0.916 & 0.976 & 0.993 & 0.970 \\
NF5 & 0.951 & 0.956 & 0.987 & 0.984 \\
NF6 & 0.919 & 0.977 & 0.980 & 0.975 \\
NF7 & 0.934 & 0.957 & 0.959 & 0.951 \\
NF8 & 0.949 & 0.930 & 0.958 & 0.823 \\
NF9 & 0.954 & 0.955 & 0.956 & 0.401 \\
\hline
\end{tabular}

\section{Discussion}

The micrometric properties of the prepared granules were found to be in the acceptable range. Angle of repose that was less than $25^{\circ}$ indicates that flow behaviour of thegranules was found to be good [38]. The FTIR studies were done to find out the compatibility between drug excipients. From the results it was suggested that there was no interaction found between drug and polymer since the peaks of the drug still could be detected in the mixture.

The weight variation and friability of all the formulations were less than $4 \%$, and $0.4 \%$ respectively. The mean thickness of NF1 was less than other formulated batches due to the reason that batch NF1 consists of a core tablet; that is, no coating was applied over it due to its thickness which was least. The thickness value of batch NF2 and NF6 was increased due to press coating with hydroxypropyl cellulose and Eudragit RLPO and RSPO mixture, and further the remaining formulations (NF3, NF4, NF5, NF7, NF8, and NF9) exhibited coating of an enteric-coated polymer over the presscoated tablets which also results in increased thickness. This might be attributed to the fact that as the coating over the tablet increases, the thickness also gets increased that can affect release of drug from coated tablets in colonic media. 


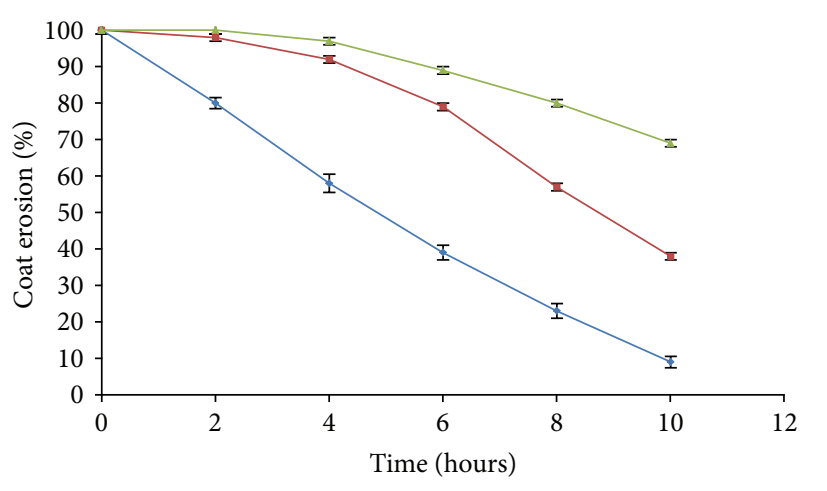

$\begin{array}{ll}\longrightarrow & \text { NF3 } \\ - & \text { NF4 } \\ \longrightarrow & \text { NF5 }\end{array}$

FIGURE 8: Coat erosion study of press-coated HPC tablets enteric coated with Eudragit S-100 in different concentrations of 2.5\%, 5.0\%, $7.5 \%$ (NF3, NF4, and NF5), respectively, without presence of rat caecal content. Data are expressed as mean \pm S.D. $(n=3)$.

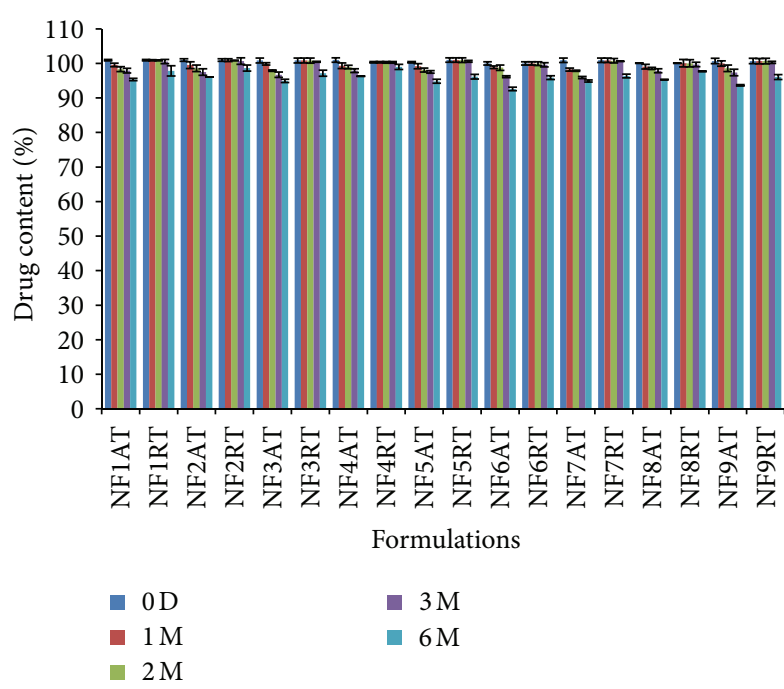

FIGURE 9: Stability of naproxen sodium tablets under accelerated condition and room temperature. Mean \pm S.D. $(n=3)$. AT: accelerated temperature $\left(40^{\circ} \mathrm{C}\right), \mathrm{RT}$ : room temperature, $\mathrm{D}$ : days, and $\mathrm{M}$ : months.

It was observed that the diameter of the coated tablets was more compared to the core tablets due to the difference in their die cavities of the tablet punching machine and also due to Eudragit S-100 coating [39]. On the other hand, the percentage friability that was less than $1 \%$ indicates that the friability is within the specified limit. The starch paste concentration resulted in a significant effect on the hardness of the tablets [40]. The increase in concentration of starch paste which acts as a binder for preparing a granules results in more hardness of the tablets. The coating is another parameter which might be increase in hardness of the coated formulation. The content uniformity for all uncoated and coated tablets was observed with minimum variation and optimum range. The maximum drug content was obtained in formulation NF2, due to the press coating of hydrophilic polymer, that is, hydroxypropyl cellulose which resulted in more marked increase in drug release rate in phosphate buffer medium.

The in vitro drug release studies were carried out of all the formulations in $\mathrm{pH} 1.2,6.8$, and 7.4, and it was observed that the tablets which were press coated with HPC or Eudragit RSPO : RLPO mixture delayed the drug release and prevent its release in gastric $\mathrm{pH}$ in comparison to the core tablet. However, due to more hydrophilic property of HPC than Eudragit RSPO : RLPO mixture, it showed high cumulative release $(79.01 \pm 2.02 \%)$ but does not remain in intact form in small intestine ( $\mathrm{pH}$ 6.8). The tablets which were press coated with Eudragit RSPO : RLPO mixture also showed premature drug release followed by sustained action (Figure 3 ) for $24 \mathrm{~h}$. Therefore, it was concluded that the coating of Eudragit S-100 was required to impart an enteric effect.

Figure 4 describes that the dissolution profile of formulations NF1 to NF5 revealed that the lag time of drug release increases with increasing the coating level of Eudragit S-100. At a coat concentration of $2.5 \% \mathrm{w} / \mathrm{v}(\mathrm{NF} 3)$, the lag time of $4 \mathrm{~h}$ was achieved; however, this lag time was insufficient to reach intact to the colon. Thus, $5 \% \mathrm{w} / \mathrm{v}$ and $7.5 \% \mathrm{w} / \mathrm{v}$ coating concentrations were needed to be applied on the press-coated tablets to prevent the drug release in upper part of GIT. By the $5 \% \mathrm{w} / \mathrm{v}$ coating (NF4), the tablet provides a desired lag time of $6 \mathrm{~h}$ and retarded the drug release in $\mathrm{pH}$ below 7.4 with cumulative drug release of $92.32 \pm 2.27 \%$. However, in case of $7.5 \% \mathrm{w} / \mathrm{v}$ coat level (NF5), the lag time was obtained up to $8 \mathrm{~h}$ with lesser cumulative release of $83.19 \pm 1.33 \%$ in comparison to formulation NF4. This can be explained by the fact that on increasing the coat concentration, the coat becomes more impermeable thereby retarding the drug release. Thus, from above results it was concluded that the formulation NF4 maintained the integrity of the coats and prevented the drug release for upto $6 \mathrm{~h}$. Finally, it was evident from the results that the tablet containing two polymeric systems showed much more site specificity than the single polymeric systems [41].

The dissolution profile of formulations NF6 to NF9 depicted in Figure 5 demonstrated the sustained action of the tablet in comparison to the core tablet. As per above discussion, the drug release from the batch NF6 provides release in small intestine due to lack of Eudragit S-100 coating. However, formulations NF7 and NF8 retarded the drug release with initial burst release with lag time of $8 \mathrm{~h}$. The combination of Eudragit RSPO : RLPO coated tablet with Eudragit S-100 coating $(7.5 \% \mathrm{w} / \mathrm{v})$ provides sustained action and no burst release, but on the other hand, this formulation showed less cumulative release profile. This phenomenon may be attributed to the combination of good erodible properties of Eudragit S-100 and the swelling behaviour of RLPO and RSPO polymer [42, 43].

The drug delivery systems targeted to the colon should not only protect the drug from being released in the physiological environment of stomach and small intestine but also release the drug in colon after enzymatic degradation by colonic bacteria. Hence, in vitro drug release studies were carried out for selected formulations in SIF (pH 7.4) containing 
$4 \% \mathrm{w} / \mathrm{v}$ of rat caecal contents. The rat caecal contents were included to mimic the colonic environment. At the end of $24 \mathrm{~h}$ of testing which includes testing in simulated gastric and intestinal fluids, the percent of drug released from naproxen tablets coated with coat formulation NF4 was found to be increase from $6 \mathrm{~h}$ onwards indicating the commencement of breaking of coats. The percent of drug released after $24 \mathrm{~h}$ of testing was $98.10 \pm 1.61 \%$ which indicates that there was more drug released in the presence of enzymes as compared to dissolution without rat caecal content. Hence, it was concluded that the dissolution study in the presence of rat caecal content resulted in improved drug release because the physiology of rat colon is similar to that of the human colon. Therefore the higher amount of drug release was observed [44].

The photomicrographs of coated tablets (Figure $7(\mathrm{a})$ ) before the dissolution study showed the presence of non porous, compact, and homogenous structure due to the coating layer of both HPC and Eudragit S-100 polymer. After $2 \mathrm{~h}$ of dissolution of tablet in $\mathrm{pH} 1.2$ media, it was observed that the tablets remain in intact form with a homogenous structure (Figure 7(b)) due to the presence of $\mathrm{pH}$-dependent polymer which does not degrade in acidic media. However, when tablets come in contact with phosphate buffer $\mathrm{pH} 6.8$, at the end of 3 hrs rare small tiny pores were observed (Figure $7(\mathrm{c})$ ), indicating the formation of a gelling structure through which solvent starts to penetrate into the porous network and hence results in the formation of tiny pores. These pores further got increased in both number and diameter in phosphate buffer pH 7.4 followed by dissolution of coating layer (Figure $7(\mathrm{~d})$ ), allowing the hydrophilic membrane to be exposed to the solvent which further accounts for the rupturing of the membrane indicating that both diffusion and erosion mechanism are responsible for release of drug. Hence, the results obtained from SEM studies of tablets may support the in vitro drug release profile as mentioned in Figure 7 [11].

The coating thickness is inversely proportional to the drug release. As the concentration of Eudragit S-100 coating increases, the drug release decreases [45]. This might be due to the fact that the more time taken by the coat to get erode when the coating concentration was increased. The erosion study suggests that $2.5 \% \mathrm{w} / \mathrm{v}$ Eudragit S-100 coating was insufficient to sustain the release more than $5 \mathrm{~h}$ due to less resistant to the erosion. However, this shows that when the enteric coating gets solubilized, the press-coated tablets get exposed to the media which release the drug at insufficient lag time. On increasing the coating concentration to $5 \% \mathrm{w} / \mathrm{v}$, the coat was found to be less eroded after $12 \mathrm{~h}$, giving the lag time of $6 \mathrm{~h}$ which is sufficient to delay the drug release to reach the colon. The drug released slowly from this system which may be attributed to its sustained action and may be due to diffusion mechanism. On further increasing coat concentration to $7.5 \% \mathrm{w} / \mathrm{v}$, the lag time of $8 \mathrm{~h}$ was obtained which suggests that the erosion of coat occurs at a very slow rate due to high coating thickness. Taking this into consideration, it was revealed that the coating level of $5.0 \% \mathrm{w} / \mathrm{v}$ was found to be optimum, because at this concentration the required lag time with sustained action of the drug release was observed.
Among the all the formulations, the formulations NF1, NF2, and NF6 followed Fickian kinetics $(n \leq 0.45)$, and the remaining formulations followed non-Fickian kinetics $(n \geq 0.45)$. This indicates that the release of naproxen sodium release from matrix tablets is diffusion for NF1, NF2 and NF6 formulations, whereas the release of naproxen sodium from remaining formulation follows the anomalous transport from matrix tablets.

The stability studies concluded that the drug degradation follows first-order kinetics. The optimized formulation NF4 showed the shelf life of more than two years which indicates that there is no need to add overages to ensure 2-year shelf life.

\section{Conclusion}

The prepared formulation was evaluated using various standard tests, and from the results it was concluded that the coating combination of both polymer, that is, HPC and Eudragit $\mathrm{S}-100$, was successful in preventing the drug release in the upper part of gastrointestinal tract. The in vitro drug release studies and SEM analysis demonstrated that the optimized formulation proved to be a promising drug delivery for colon targeting. The release kinetics of all the batches were best fitted to Korsmeyer-Peppas model and Higuchi model. The stability data suggested the lowest degradation and maximum shelf life as per ICH guidelines.

\section{Conflict of Interests}

The authors report no conflict of interests.

\section{Acknowledgments}

The authors are thankful to Micro Labs Pvt. Ltd., Bangalore, India, and Evonik Industries Mumbai, India, for providing naproxen sodium and Eudragit S-100, respectively. The authors are grateful to Dr. Madhu Chitkara, Vice chancellor, Chitkara University, Rajpura, Punjab, for financial and infrastructure support for the project.

\section{References}

[1] A. K. Philip and B. Philip, "Colon targeted drug delivery systems: a review on primary and novel approaches," Oman Medical Journal, vol. 25, no. 2, pp. 70-78, 2010.

[2] P. Kumar and B. Mishra, "Colon targeted drug delivery systems-an overview," Current Drug Delivery, vol. 5, no. 3, pp. 186-198, 2008.

[3] T. Bussemer, I. Otto, and R. Bodmeier, "Pulsatile drug-delivery systems," Critical Reviews in Therapeutic Drug Carrier Systems, vol. 18, no. 5, pp. 433-458, 2001.

[4] D. R. Friend, "Colon-specific drug delivery," Advanced Drug Delivery Reviews, vol. 7, no. 1, pp. 149-199, 1991.

[5] D. R. Friend, "New oral delivery systems for treatment of inflammatory bowel disease," Advanced Drug Delivery Reviews, vol. 57, no. 2, pp. 247-265, 2005.

[6] N. K. Thakral, A. R. Ray, D. Bar-Shalom, A. H. Eriksson, and D. K. Majumdar, "The quest for targeted delivery in colon cancer: 
mucoadhesive valdecoxib microspheres," International Journal of Nanomedicine, vol. 6, pp. 1057-1068, 2011.

[7] A. Lamprecht, N. Ubrich, H. Yamamoto et al., "Biodegradable nanoparticles for targeted drug delivery in treatment of inflammatory bowel disease," Journal of Pharmacology and Experimental Therapeutics, vol. 299, no. 2, pp. 775-781, 2001.

[8] A. Yamamoto, "Study on the colon specific delivery of prednisolone using chitosan capsules," Yakugaku Zasshi, vol. 127, no. 4, pp. 621-630, 2007.

[9] L. Hovgaard and H. Brøndsted, "Dextran hydrogels for colonspecific drug delivery," Journal of Controlled Release, vol. 36, no. 1-2, pp. 159-166, 1995.

[10] P. R. Veerareddy and R. P. Manthri, "Formulation and evaluation of compression coated piroxicam tablets for colon specific drug delivery," Acta Pharmaceutica Sciencia, vol. 52, no. 3, pp. 281-284, 2010.

[11] A. Chaudhary, N. Tiwari, V. Jain, and R. Singh, "Microporous bilayer osmotic tablet for colon-specific delivery," European Journal of Pharmaceutics and Biopharmaceutics, vol. 78, no. 1, pp. 134-140, 2011.

[12] K. P. Rao, B. Prabhashankar, A. Kumar et al., "Formulation and roentgenographic studies of naproxen-pectin-based matrix tablets for colon drug delivery," Yale Journal of Biology and Medicine, vol. 76, no. 4-6, pp. 149-154, 2003.

[13] M. Z. I. Khan, H. P. Štedul, and N. Kurjaković, "A pH-dependent colon-targeted oral drug delivery system using methacrylic acid copolymers. II. Manipulation of drug release using Eudragit L100 and Eudragit S100 combinations," Drug Development and Industrial Pharmacy, vol. 26, no. 5, pp. 549-554, 2000.

[14] K. Verbeke, V. de Preter, K. Geboes et al., "In vivo evaluation of a colonic delivery system using isotope techniques," Alimentary Pharmacology and Therapeutics, vol. 21, no. 2, pp. 187-194, 2005.

[15] A. Gazzaniga, C. Busetti, L. Moro, M. E. Sangalli, and F. Giordano, "Time-dependent oral delivery systems for colon targeting," S.T.P. Pharma Sciences, vol. 5, no. 1, pp. 83-88, 1995.

[16] B. Wu, N. Shun, X. Wei, and W. Wu, "Characterization of 5fluorouracil release from hydroxypropylmethylcellulose compression-coated tablets," Pharmaceutical Development and Technology, vol. 12, no. 2, pp. 203-210, 2007.

[17] M. Muraoka, Z. Hu, T. Shimokawa et al., "Evaluation of intestinal pressure-controlled colon delivery capsule containing caffeine as a model drug in human volunteers," Journal of Controlled Release, vol. 52, no. 1-2, pp. 119-129, 1998.

[18] I. Krögel and R. Bodmeier, "Floating or pulsatile drug delivery systems based on coated effervescent cores," International Journal of Pharmaceutics, vol. 187, no. 2, pp. 175-184, 1999.

[19] D. A. Quinteros, R. H. Manzo, and D. A. Allemandi, "Design of a colonic delivery system based on cationic polymethacrylate (Eudragit E100)-mesalamine complexes," Drug Delivery, vol. 17, no. 4, pp. 208-213, 2010.

[20] R. C. Rowe, P. J. Sheskey, and M. E. Quinn, Handbook of Pharmaceutical Excipients, Pharmaceutical Press, RPS Publishing, London, UK, 6th edition, 2009.

[21] E. Fukui, K. Uemura, and M. Kobayashi, "Studies on applicability of press-coated tablets using hydroxypropylcellulose (HPC) in the outer shell for timed-release preparations," Journal of Controlled Release, vol. 68, no. 2, pp. 215-223, 2000.

[22] K. M. Picker-Freyer and T. Durig, "Physical mechanical and tablet formation properties of hydroxypropyl cellulose: in pure form and in mixtures," AAPS PharmSciTech, vol. 8, no. 4, pp. 82-90, 2007.
[23] D. Desai, F. Rinaldi, S. Kothari et al., "Effect of hydroxypropyl cellulose (HPC) on dissolution rate of hydrochlorothiazide tablets," International Journal of Pharmaceutics, vol. 308, no. 1-2, pp. 40-45, 2006.

[24] N. N. Mohammed, S. Majumdar, A. Singh et al., "KlucelTM EF and ELF polymers for immediate-release oral dosage forms prepared by melt extrusion technology," AAPS PharmSciTech, vol. 13, no. 4, pp. 1158-1169, 2012.

[25] N. Kotagale, M. Maniyar, S. Somvanshi, M. Umekar, and C. J. Patel, "Eudragit-S, Eudragit-L and cellulose acetate phthalate coated polysaccharide tablets for colonic targeted delivery of azathioprine," Pharmaceutical Development and Technology, vol. 15, no. 4, pp. 431-437, 2010.

[26] S. C. Sweetman, Martindale: The Complete Drug Reference, Pharmaceutical Press, London, UK, 35th edition, 2007.

[27] H. J. Berkel, R. F. Holcombe, M. Middlebrooks, and K. Kannan, "Nonsteroidal antiinflammatory drugs and colorectal cancer," Epidemiologic Reviews, vol. 18, no. 2, pp. 205-217, 1996.

[28] Z. Z. Piao, M. K. Lee, and B. J. Lee, "Colonic release and reduced intestinal tissue damage of coated tablets containing naproxen inclusion complex," International Journal of Pharmaceutics, vol. 350, no. 1-2, pp. 205-211, 2008.

[29] M. M. Patel, S. L. Patel, M. N. Bhadani, T. J. Shah, and A. F. Amin, "A synchronous colon-specific drug delivery system for orally administered mesalamine," Acta Pharmaceutica Sciencia, vol. 51, no. 3, pp. 251-260, 2009.

[30] V. R. Sinha and R. Kumria, "Polysaccharide matrices for microbially triggered drug delivery to the colon," Drug Development and Industrial Pharmacy, vol. 30, no. 2, pp. 143-150, 2004.

[31] V. R. Sinha, A. Singh, S. Singh, and J. R. Bhinge, "Compression coated systems for colonic delivery of 5-fluorouracil," Journal of Pharmacy and Pharmacology, vol. 59, no. 3, pp. 359-365, 2007.

[32] C. Dabhi, S. Randale, V. Belgamwar, S. Gattani, and A. Tekade, "Predictable pulsatile release of tramadol hydrochloride for chronotherapeutics of arthritis," Drug Delivery, vol. 17, no. 5, pp. 273-281, 2010.

[33] S. Rujivipat and R. Bodmeier, "Improved drug delivery to the lower intestinal tract with tablets compression-coated with enteric/nonenteric polymer powder blends," European Journal of Pharmaceutics and Biopharmaceutics, vol. 76, no. 3, pp. 486492, 2010.

[34] P. Costa and J. M. S. Lobo, "Modeling and comparison of dissolution profiles," European Journal of Pharmaceutical Sciences, vol. 13, no. 2, pp. 123-133, 2001.

[35] ICH-Q1A (R2), "Stability testing of new drug substances and products," in Proceedings of the International Conference on Harmonization, Geneva, Switzerland, February 2003.

[36] K. S. Soppimath, A. R. Kulkarni, and T. M. Aminabhavi, "Chemically modified polyacrylamide-g-guar gum-based crosslinked anionic microgels as $\mathrm{pH}$-sensitive drug delivery systems: preparation and characterization," Journal of Controlled Release, vol. 75, no. 3, pp. 331-345, 2001.

[37] M. C. Gohel, R. K. Parikh, S. A. Nagori, and M. R. Dabhi, "Design of a potential colonic drug delivery system of mesalamine," Pharmaceutical Development and Technology, vol. 13, no. 5, pp. 447-456, 2008.

[38] J. I. Wells and M. E. Aulton, "Pharmaceutical preformulation," in The Design and Manufacture of Medicines, M. E. Aulton, Ed., pp. 336-360, Churchill Livingstone, Elsevier Press, Beijing, China, 2008. 
[39] R. Shah, S. Patel, H. Patel, S. Pandey, S. Shah, and D. Shah, "Formulation development of carvedilol compression coated tablet," Pharmaceutical Developement and Technology, vol. 18, no. 4, pp. 906-915, 2013.

[40] R. K. Dev, V. Bali, and K. Pathak, "Novel microbially triggered colon specific delivery system of 5-fluorouracil: statistical optimization, in vitro, in vivo, cytotoxic and stability assessment," International Journal of Pharmaceutics, vol. 411, no. 1-2, pp. 142151, 2011.

[41] J. Alvarez-Fuentes, M. Fernández-Arévalo, M. L. GonzálezRodríguez, M. Cirri, and P. Mura, "Development of entericcoated timed-release matrix tablets for colon targeting," Journal of Drug Targeting, vol. 12, no. 9-10, pp. 607-612, 2004.

[42] A. Kuksal, A. K. Tiwary, N. K. Jain, and S. Jain, "Formulation and in vitro, in vivo evaluation of extended-release matrix tablet of zidovudine: influence of combination of hydrophilic and hydrophobic matrix formers," AAPS PharmSciTech, vol. 7, no. 1, pp. E1-E9, 2006.

[43] C. N. Patra, A. B. Kumar, H. K. Pandit, S. P. Singh, and M. V. Devi, "Design and evaluation of sustained release bilayer tablets of propranolol hydrochloride," Acta Pharmaceutica, vol. 57, no. 4, pp. 479-489, 2007.

[44] R. Dubey, R. Dubey, P. Omrey, S. P. Vyas, and S. K. Jain, "Development and characterization of colon specific drug delivery system bearing 5-ASA and camylofine dihydrochloride for the treatment of ulcerative colitis," Journal of Drug Targeting, vol. 18, no. 8, pp. 589-601, 2010.

[45] M. Z. I. Khan, Z. Prebeg, and N. Kurjaković, "A pH-dependent colon targeted oral drug delivery system using methacrylic acid copolymers. I. Manipulation of drug release using Eudragit L100-55 and Eudragit S100 combinations," Journal of Controlled Release, vol. 58, no. 2, pp. 215-222, 1999. 

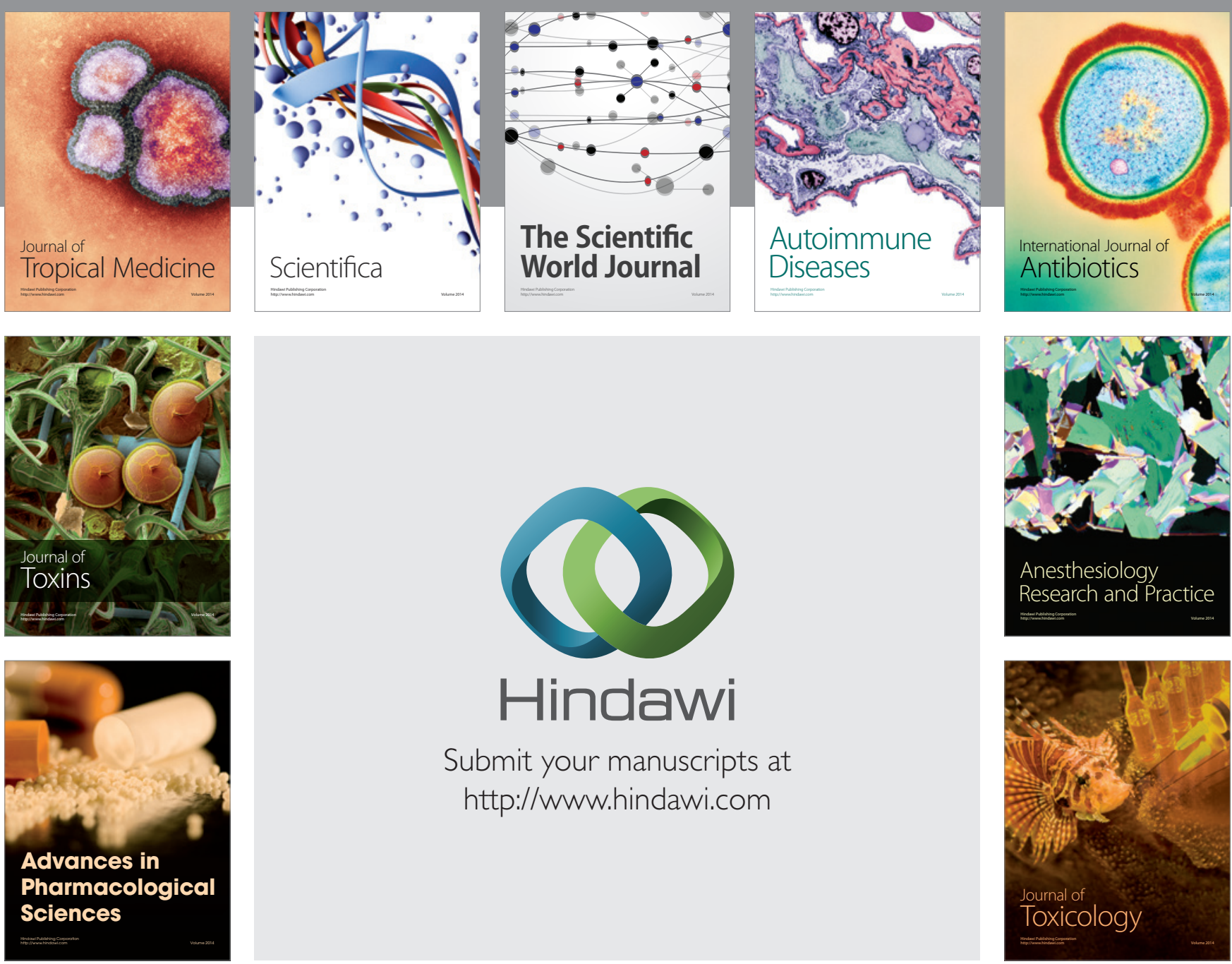

\section{Hindawi}

Submit your manuscripts at

http://www.hindawi.com
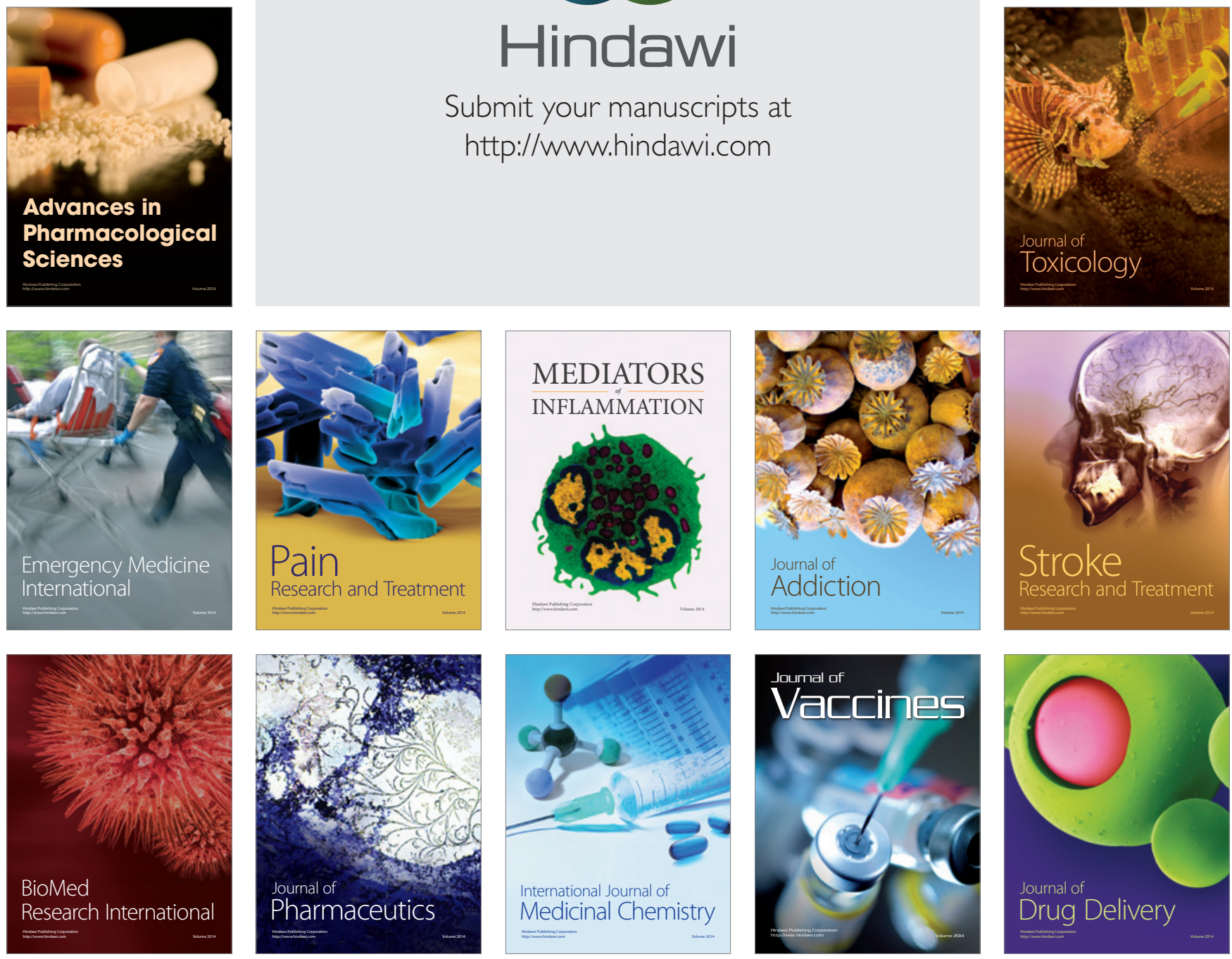